\title{
Accidental ingestion of BiTine ring and a note on inefficient ring separation forceps
}

\author{
This article was published in the following Dove Press journal: \\ Therapeutics and Clinical Risk Management \\ 23 May 2011 \\ Number of times this article has been viewed
}

\author{
Om Nemichand Baghele' \\ Mangala Om Baghele ${ }^{2}$ \\ 'Department of Periodontology, \\ SMBT Dental College and Hospital, \\ Sangamner, Ahmednagar, Maharashtra, \\ India; ${ }^{2}$ Private General Dental \\ Practice, Mumbai, India
}

Background: Accidental ingestion of medium-to-large instruments is relatively uncommon during dental treatment but can be potentially dangerous. A case of BiTine ring ingestion is presented with a note on inefficient ring separation forceps.

Case description: A 28-year-old male patient accidentally ingested the BiTine ring ( $2 \mathrm{~cm}$ diameter, $0.5 \mathrm{~cm}$ outward projections) while it was being applied to a distoproximal cavity in tooth \# 19. The ring placement forceps were excessively flexible; bending of the beaks towards the ring combined with a poor no-slippage mechanism led to sudden disengagement of the ring and accelerated movement towards the pharynx. We followed the patient with bulk forming agents and radiographs. Fortunately the ring passed out without any complications.

Clinical implications: Checking equipment and methods is as important as taking precautions against any preventable medical emergency. It is the responsibility of the clinician to check, verify and then use any instrument/equipment.

Keywords: foreign bodies/radiography, foreign bodies/complications, equipment failure, dental instrument, accidental ingestion

\section{Introduction}

Although rare and unfortunate, accidental ingestion of medium-to-large foreign bodies of dental origin has been reported in various case reports. ${ }^{1-3}$ Foreign object ingestion and food bolus impaction occur commonly. The majority of foreign bodies that reach the gastrointestinal tract (GIT), ie, true foreign objects and food bolus impactions, will pass out spontaneously. However, $10 \%$ to $20 \%$ will require non-operative intervention, and $1 \%$ or less will require surgery. ${ }^{4-6}$ The majority of foreign body ingestions occur in the pediatric population with a peak incidence between ages 6 months and 6 years. ${ }^{4,7-9}$ It is a common pediatric problem, with more than 100,000 cases occurring each year in the USA. ${ }^{10}$ However, it is not uncommon to find foreign body ingestion in adults as well. In adults, true foreign object ingestion occurs more commonly among those with psychiatric disorders, mental retardation, or impairment caused by alcohol, and those seeking some secondary gain with access to a medical facility.,11 The origin of foreign bodies is varied, but the second most likely object to be ingested is dental in origin. ${ }^{12}$ Edentulous adults are also at greater risk for foreign body ingestion, including of their dental prosthesis. ${ }^{11,13}$

Fixed prosthodontic therapy has the highest number of incidents of adverse outcomes. Ingestion is a more prevalent outcome than aspiration. Dental procedures involving single tooth casts or prefabricated restorations involving cementation have a higher likelihood of aspiration. ${ }^{12}$ Although precautionary measures should always be taken, the incidence 
of ingestion or aspiration of endodontic instruments is low (aspiration 0.001 per 100,000 root canal treatments, ingestion 0.12 per 100,000 root canal treatments) even though most general practitioners do not routinely use rubber dams. ${ }^{14}$

Immediate complications such as acute airway obstruction and hypoxia and chronic complications such as esophageal erosion and pneumonia resulting from unrecognized aspiration or ingestion are serious medical issues that require further care and hospitalization. These complications not only have associated economic cost, but also carry the risk of malpractice litigation against the dentist. ${ }^{15}$

We wanted to report this case because of the scarcity of documented instances of ingestion and aspiration of foreign bodies of dental origin and no reported case of a medium sized ring with pointed, outward-projecting tines. We also believed that a closer examination of the circumstances surrounding the ingestion was warranted and we wanted to evaluate the inefficiency of a dental product being supplied for the purposes of ring separation, which played a major role in the accidental ingestion event.

\section{Case report}

A male patient, aged 28 years, reported to the clinic for repair of a failed restoration in the mandibular left first molar (\# 19) tooth. The patient was systemically healthy with appropriate gait and demeanor. No history of any previous hospitalization or any systemic disease, drug allergy, or long term medicinal therapy was noted. Dental history was positive with many silver amalgam restorations to several teeth. The patient complained of a broken silver amalgam filling in tooth \# 19. The patient reported no history of pain or severe discomfort in the tooth, but some hypersensitivity to cold, hot and sweet foodstuffs. On local examination it was confirmed that the tooth had a fractured distoproximal silver amalgam filling. Pain on percussion was absent and there was no local periapical pathology or submandibular lymphadenopathy. On closer examination the cavitation looked deep and a decision to give a tissue-friendly dressing for few days and observe for pulpal reaction was taken. All possibilities and the treatment plan were then explained to the patient. The patient agreed to the plan we suggested, but he wanted a composite restoration instead of the earlier silver amalgam filling.

At the next appointment the silver amalgam filling was removed and a dressing comprised of calcium hydroxide and zinc oxide eugenol was placed. The patient was recalled after three weeks and it was noted that the patient was asymptomatic: the pulp reacted very positively. Then it was decided to do the final filling with composite restorative material. The earlier dressing was removed, keeping a sub-base of calcium hydroxide, and a small increment of restorative glass ionomer cement was added. To make proper contact points, we tried to place the round Palodent BiTine ring (Dentsply Caulk, Milford, DE) after placing the standard Palodent sectional matrix properly according to the manufacturer's instructions. We used the Palodent BiTine Placement Forceps for spreading the BiTine ring supplied by the manufacturer with the kit. As the forceps' beaks bend unfavorably when applying the ring to the tooth, and the holding mechanism against slippage is poor, there was a forceful disengagement of the ring and the ring disappeared out of sight very rapidly. We tried to locate the ring but could not ascertain its location immediately. The patient then informed us that something went inside his pharynx and he swallowed it. We confirmed the finding that the patient indeed ingested the Palodent BiTine round ring. On questioning, he stated that this had happened before, and that he has hyper-responsive pharyngeal reflexes. On the earlier occasion he ingested some dental material while under treatment from a different dental practitioner. We also noted that he would not let us keep the suction tip near his oropharynx and that most of the time he ingested the secretions and the water accumulated at the pharynx, unlike other normal patients. He appeared calm, composed, non-apprehensive and fearless even after knowing that he had ingested a metal ring of $2.0 \mathrm{~cm}$ diameter with two $0.5 \mathrm{~cm}$ outward projections. As the patient did not reported any pain or discomfort while ingesting or thereafter, we refrained from taking any emergency radiographs. We stopped the dental treatment and placed a temporary filling again. We gave a lot of water to drink, reassured the patient and advised him to take a lot of bulk-forming agents in the form of bananas and ispaghula (a natural colloidal mucilage which forms a gelatinous mass by absorbing water: 3-4 g of refined husk freshly mixed with water or milk and taken three times a day). He was also advised on antibiotic coverage (ciprofloxacin $500 \mathrm{mg}$ twice a day and metronidazole $400 \mathrm{mg} 3$ times a day for at least 3 days initially). He was advised to keep an eye on various related signs and symptoms and also whether he noticed the object passing through his stools. Because the patient did not report difficulty in swallowing or respiratory difficulty (choking, inspiratory stridor or forced breathing) we assumed that the airway was clear. The patient was asked to note any pain, vomiting, gagging, salivary drooling, retching, tenderness, nausea, reduced appetite, abdominal discomfort, difficulty in bowel movements, or blood in the stools. A radiologist and a gastroenterologist were consulted telephonically and possible arrangements were kept ready. 
We were more concerned about the two parallel outwards projections of the ring than the ring structure itself. The projections had the potential to embed in tissues such as sphincters, curvatures of the GIT, or internal foldings of the intestinal mucosa.

The patient was $\mathrm{x}$-rayed (standing abdomen antero-posterior view) the next day, almost 13 hours after the incident (Figure 1). The radiologist noted that the ring was present in the pelvis, mostly in the sigmoidal colon, and it would be prudent to wait for 24 to 48 hours and repeat the radiograph. The patient continued with antibiotic coverage and bulk forming agents. About 37 hours after the incident we repeated the radiograph (Figure 2) and saw no radio-opaque body. We were relieved, and the patient became happier. The patient did not notice when it passed in feces.

\section{The timeline}

Day 1: Patient accidentally ingested the ring: 26/11/2009: $09.00 \mathrm{pm}$ : No symptoms.

Day 2: Patient took the first radiograph: 27/11/2009: 10.20 am: Ring in the pelvic region.

Day 3: Patient took the second radiograph: 28/11/2009: 10.40 am: No ring visible.

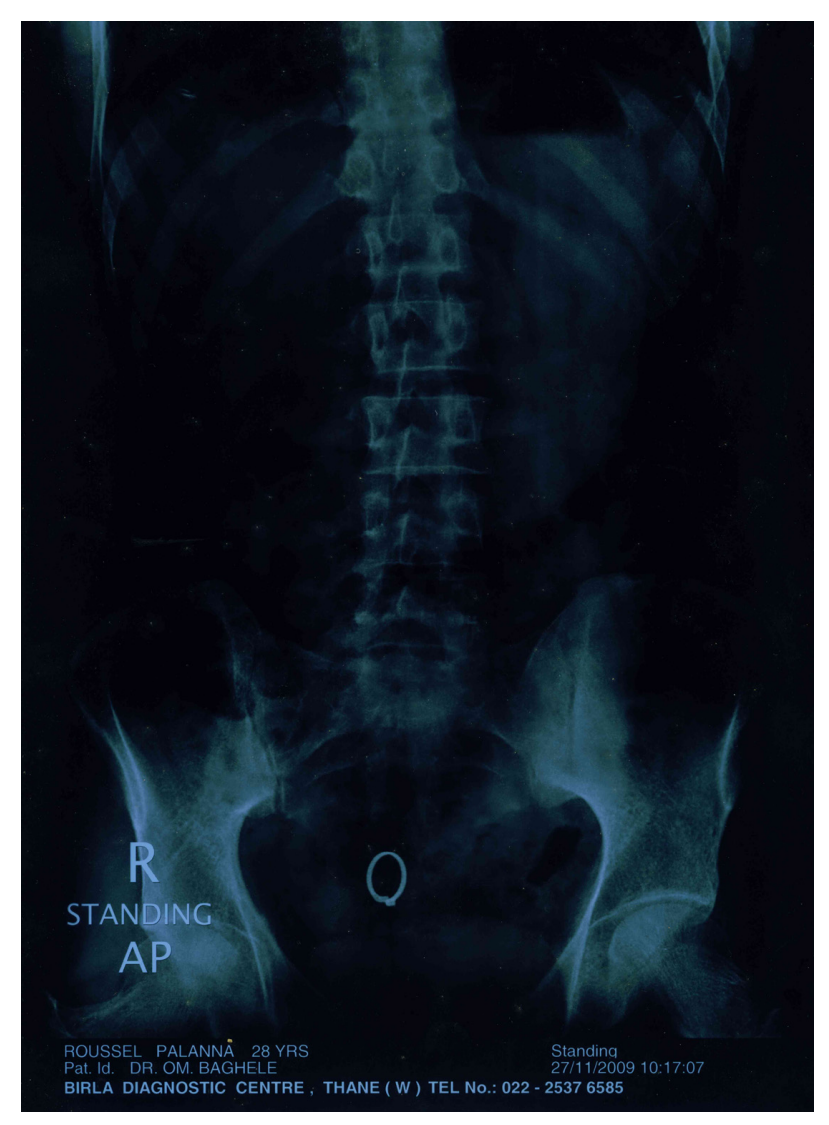

Figure I Radiograph showing the metal ring in pelvic region.

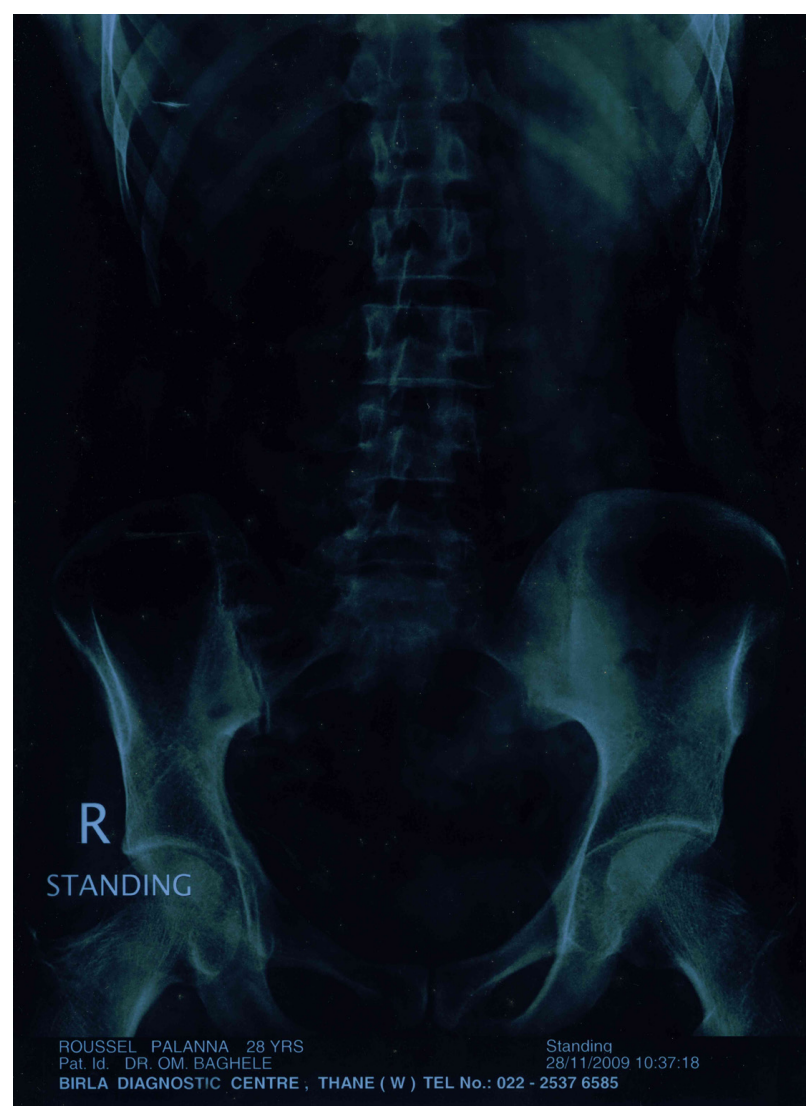

Figure 2 Radiograph of abdomen: no metallic objects visible.

\section{Forceps for ring separation}

We tried to ascertain why the event happened in the first place. We noted that some of the problem lies with the Palodent forceps supplied with the kit, which are excessively flexible and unsuitable for applying rings, especially on molars. As the forceps are supplied with the matrix bands-rings-forceps kit (Figure 3), naturally they will be used instead of any other rigid forceps. Although the instructions given along with the kit mention that rubber dam forceps should be used for spreading out the rings, why should they provide these forceps with the kit? The instructions on their specific use are missing in the instruction manual but the accompanying pamphlet mentions, "BiTine Placement Forceps: firm hold of the BiTine ring during placement and removal". That appears to mean they are to be used for spreading out the rings. However, the forceps have two inherent problems which render them unsuitable for spreading rings.

\section{Excessive flexibility}

The whole instrument is not rigid. Both its tines and handles bend towards the long axis of the instrument when applying ring separation force to the forceps (Figure 4). As the rigidity 


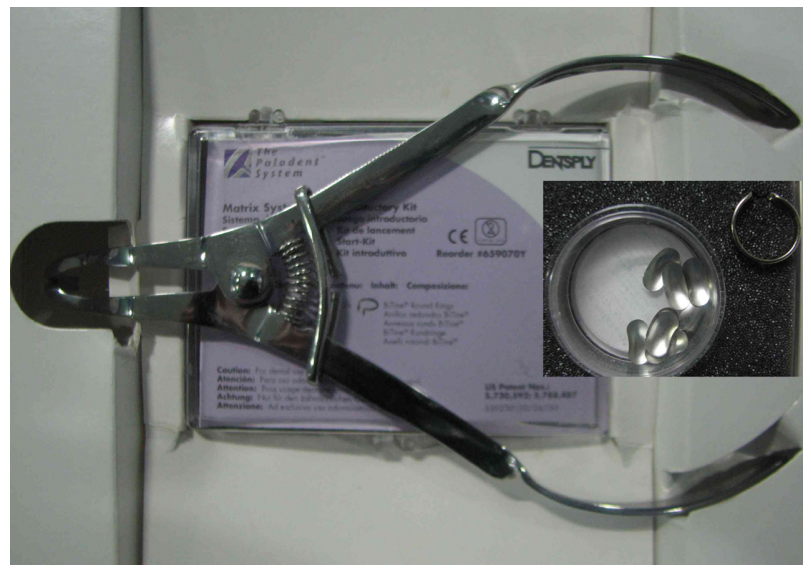

Figure 3 The Palodent forceps, matrix bands and the round ring kit.

of the ring is much higher than that of the forceps, there is maximum flexion at the bend present on the active beak side. Comparing the forceps with any rigid forceps, the difference is very apparent (Figure 5). The beaks are also thinner than those on other forceps. There is no bending or flexion of any rigid forceps (Figure 6). The instrument is very thin, although flat in design in an attempt to compensate for forces, which allows a lot of flexibility. Because of the flexion, the parallelism of the holding tines is lost and they slant towards the ring, providing an easy escape for the ring when under force.

\section{Poor slippage resistance notches}

The Palodent forceps' ring holding notches are shallow and poorly engineered. The notching should have been deep and serrated to prevent the slippage of rings and to compensate for the flexion of the instrument (which was not expected in the first place). Because of the slanting of the tines towards the rings, the notches become inefficient,

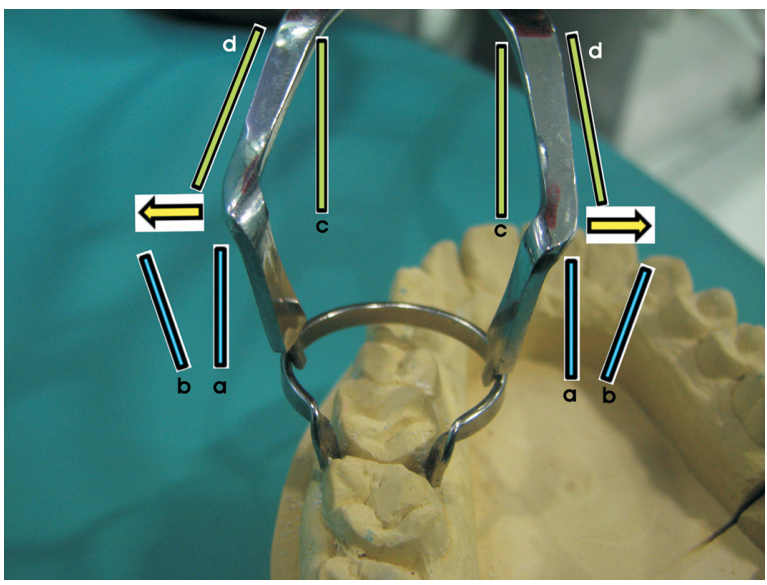

Figure 4 Evaluation of the flexibility of Palodent forceps: arrows denote the direction of flexure; vertical lines denote how the instrument should be without bending.

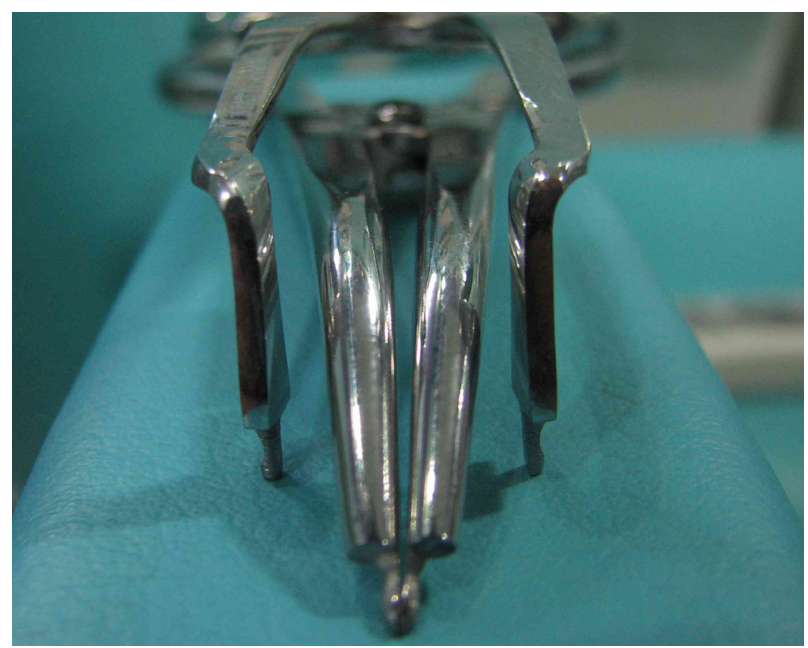

Figure 5 Comparing the beaks of a prototype rigid ring placement forceps with Palodent forceps.

increasing the chances of slippage. Ring separation forces are usually more when applied for ring removal after the restoration; the chances of ring slippage are higher during this part of the procedure.

\section{Other ring separation forceps}

The use of rubber dam forceps for ring separation is well documented and advised because of the rigidity of the instrument and ease of use. They are readily available in all clinics in the developed world but may not be used routinely in developing and underdeveloped countries. Other specially designed forceps (Figure 6) for ring separation may be very rigid and limited in their applications. Any forceps used for ring separation should have appropriate engineering specifications: rigidity; slippage prevention notches; ring holding beaks; no flexibility; ease of use and maneuverability.

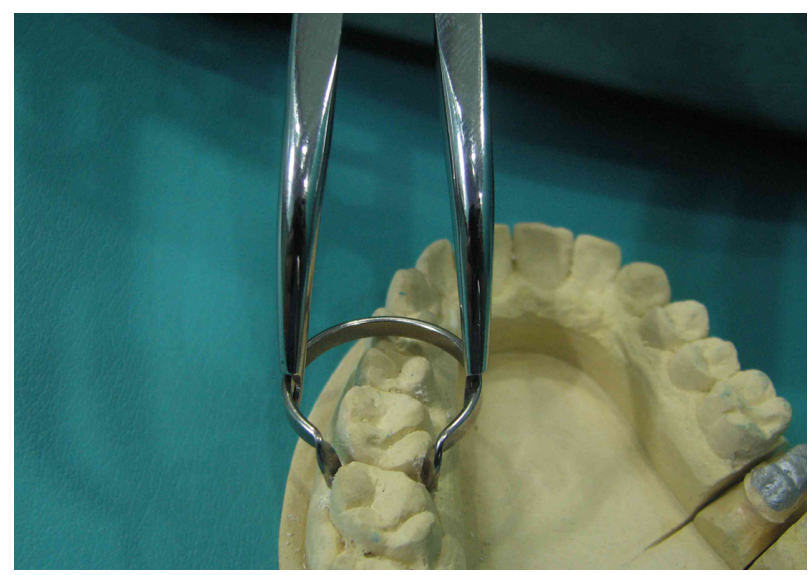

Figure 6 Engaging the ring with a prototype rigid forceps: notice no flexibility of the beaks. 


\section{Discussion}

Accidental ingestion of foreign bodies of dental origin is not very common and most small and blunt objects will pass out uneventfully. However, it is a matter of concern if any sharp object, or a bigger object, is accidentally ingested. Foreign body ingestion is a common endoscopic emergency (second in frequency only to gastrointestinal bleeding) and is usually a benign condition in the upper gastrointestinal tract. ${ }^{16}$ Impaction, perforation, or obstruction most often occurs at areas of acute angulations or physiologic narrowing. Patients with prior gastrointestinal tract surgery or congenital gut malformations are at an increased risk for obstruction or perforation. ${ }^{17}$ Toothbrush ingestion may lead to duodenal perforation, ${ }^{18}$ and complications as remote as constrictive pericarditis, ${ }^{19}$ subcutaneous emphysema of the $\operatorname{leg}^{20}$ and delayed death ${ }^{21}$ have been reported to toothpick ingestion.
Our patient ingested a ring, $2 \mathrm{~cm}$ in diameter and with two $0.5 \mathrm{~cm}$ outward projections, which can be regarded as a medium-sized sharp object. We were very much concerned about the impaction of the ring inside the alimentary canal and possible perforation of the mucosa by the projecting tines. Throughout the episode the patient was very much poised and stable, maybe because he had an earlier experience of similar accidental ingestion. The patient reported and was aware of increased sensitivity at the oropharyngeal area. The patient could not tolerate anything in that area: even the tip of the suction tube evoked a strong pharyngeal reflex.

Taking precautions while doing any clinical procedure is of paramount importance. We failed to tie a sterile string or floss to the ring. Attaching a string may have allowed easy retrieval or prevented the episode. The use of rubber dams in our country is limited and usually carried out in institutions or by trained endodontists. Use of rubber dams

Table I Guidelines for imaging of foreign bodies ingested/inhaled ${ }^{23}$

\begin{tabular}{|c|c|c|c|c|}
\hline Class & Clinical problem & Investigation & Recommendation & Comment \\
\hline K 28 & $\begin{array}{l}\text { Soft tissue injury: FB } \\
\text { (metal, glass, painted } \\
\text { wood) }\end{array}$ & $X R$ & Indicated & $\begin{array}{l}\text { All glass is radio-opaque; some paint is radio-opaque. } \\
\text { Radiography and interpretation may be difficult; } \\
\text { remove blood-stained dressings first. Consider US, } \\
\text { especially in areas where radiography difficult. }\end{array}$ \\
\hline K 29 & $\begin{array}{l}\text { Soft tissue injury: FB } \\
\text { (plastic, wood) }\end{array}$ & $\begin{array}{l}X R \\
\text { US }\end{array}$ & $\begin{array}{l}\text { Not indicated routinely } \\
\text { Indicated }\end{array}$ & $\begin{array}{l}\text { Plastic is not radio-opaque: wood is rarely radio- } \\
\text { opaque. Soft-tissue US may show non-opaque FB. }\end{array}$ \\
\hline K 30 & $\begin{array}{l}\text { Swallowed FB suspected } \\
\text { in pharyngeal or upper } \\
\text { esophageal region (for } \\
\text { children see Section } M-23 \text { ) }\end{array}$ & $\begin{array}{l}X R \text { soft tissues of neck } \\
A X R\end{array}$ & $\begin{array}{l}\text { Indicated } \\
\text { Not indicated routinely }\end{array}$ & $\begin{array}{l}\text { After direct examination of oropharynx (where } \\
\text { most FBs lodge), and if FB likely to be opaque. } \\
\text { Differentiation from calcified cartilage can be } \\
\text { difficult. Most fish bones invisible on XR. Maintain } \\
\text { a low threshold for laryngoscopy or endoscopy, } \\
\text { especially if pain persists after } 24 \text { hours (see K33). }\end{array}$ \\
\hline K 31 & $\begin{array}{l}\text { Swallowed FB: smooth } \\
\text { and small (eg, coin) }\end{array}$ & $\begin{array}{l}C X R \\
A X R\end{array}$ & $\begin{array}{l}\text { Indicated } \\
\text { Not indicated routinely }\end{array}$ & $\begin{array}{l}\text { The minority of swallowed FBs will be radio-opaque. } \\
\text { In children a single, slightly over-exposed, frontal } \\
\text { CXR to include neck should suffice. In adults, } \\
\text { a lateral CXR may be needed in addition if frontal } \\
\text { CXR negative. Majority of FBs that impact, do so } \\
\text { at crico-pharyngeus. If the FB has not passed (say } \\
\text { within } 6 \text { days), AXR may be useful for localization. }\end{array}$ \\
\hline K 32 & $\begin{array}{l}\text { Sharp or potentially } \\
\text { poisonous swallowed FB: } \\
\text { (eg, battery) }\end{array}$ & $\begin{array}{l}A X R \\
C X R\end{array}$ & $\begin{array}{l}\text { Indicated } \\
\text { Not indicated routinely }\end{array}$ & $\begin{array}{l}\text { Most swallowed foreign bodies that pass the } \\
\text { esophagus eventually pass through the remainder } \\
\text { of the gastrointestinal tract without complication. } \\
\text { But location of batteries is important as leakage } \\
\text { can be dangerous. Unless AXR negative. }\end{array}$ \\
\hline K 33 & $\begin{array}{l}\text { Swallowed FB: large object } \\
\text { (eg, dentures) }\end{array}$ & $C X R$ & Indicated & $\begin{array}{l}\text { Dentures vary in radio-opacity; most plastic } \\
\text { dentures are radiolucent. AXR may be needed } \\
\text { if CXR negative, as may barium swallow or } \\
\text { endoscopy. Lateral CXR may be helpful. }\end{array}$ \\
\hline M 23 & $\begin{array}{l}\text { Inhaled FB (suspected) } \\
\text { in children }\end{array}$ & $C X R$ & Indicated & $\begin{array}{l}\text { History of inhalation often not clear. Bronchoscopy } \\
\text { is indicated, even in the presence of a normal CXR. } \\
\text { NM/CT may be helpful to show subtle air trapping. } \\
\text { Wide variation in local policy about expiratory films, } \\
\text { fluoroscopy, CT and NM (ventilation scintigraphy). }\end{array}$ \\
\hline
\end{tabular}

Abbreviations: FB, Foreign body; XR, Plain radiography one or more films; CXR, Chest radiograph; AXR, Abdominal radiograph; US, Ultrasound; CT, Computed tomography; NM, Nuclear medicine. 
by general practitioners for endodontic procedures should be encouraged by stressing its advantages rather than the fear factor of accidents. ${ }^{14}$

Even though we refrained from taking immediate radiographs, radiographic examination is mandatory for differential diagnosis of the location, nature and size of a foreign body. This can begin with the acquisition of anteroposterior and lateral chest, lateral neck and supine abdominal radiographs to complete the evaluation from the nasopharynx to the rectum. The major limitation of the initial radiographic evaluation is the potential failure to visualize a radiolucent object. In this scenario, locating the foreign body may be difficult, requiring endoscopic examination, computed tomography, or simple monitoring of physical signs. ${ }^{22}$ Reference guidelines for radiologists for foreign body ingestion/inhalation have been outlined by the European Commission $^{23}$ (Refer to Table 1).

Once through the esophagus, the majority of ingested foreign bodies pass through the alimentary tract uneventfully, including sharp-pointed objects. ${ }^{4-6}$ Most objects are passed within 4 to 6 days, although some may take as long as 4 weeks. While awaiting spontaneous passage of a foreign body, patients are usually instructed to continue a regular diet and observe their stools for the ingested object. In the absence of symptoms, weekly radiographs are sufficient to follow the progression of small blunt objects not observed to pass spontaneously. ${ }^{4,6}$ The management protocol for ingested foreign bodies remaining in the GIT for longer periods has been described by Bisharat et $\mathrm{al}^{24}$ studying prisoners who were known to deliberately ingest various objects. Daily to weekly radiographs have been advised depending on the size of the foreign body, its position and progress up to 2 months. For sharp metallic objects daily radiographic examination is necessary and for blunt metallic objects even weekly radiographs would be enough. ${ }^{24}$

Our patient passed the ring within 37 hours of ingestion without noticing it and without any signs or symptoms of foreign body ingestion. The ring structure, along with bulkforming agents, might have aided the smooth passage of the object through the GIT.

\section{Conclusion}

Equipment and methods are of immense importance in any dental clinical procedure, especially if other forms of precautions are not followed. We naturally used the forceps which were supplied with the kit for ring separation, but the inherent problems with the forceps led to slippage of the ring and accidental ingestion in the absence of tied floss. Rigid forceps with good non-slippage notches would have prevented the accidental slippage of the ring.

It is prudent to watch for the ingested object for few days to see if it passes out naturally, in the absence of specific signs and symptoms. It is also important to ascertain the movement of the object by taking sequential radiographs at specified intervals. Although modern dental techniques have reduced the necessity of using rubber dams in some instances (eg, high vacuum suctions, 4-handed/6-handed dentistry, refined and advanced quick techniques, gels instead of liquids for various procedures, secretion-reducing medications, and the use of lasers), prevention against dental object ingestion/inhalation should be prioritized. Use should be made of suitable preventive strategies, including the use of rubber dams, depending upon the procedure being carried out, and appropriate instruments and manpower should be made available.

For any endodontic or restorative procedures it is imperative to use rubber dams to avoid potentially serious complications. Good professional conduct and sticking to evidence-based guidelines can prevent most injuries and complications in the clinic, despite failures or deficiencies of the materials employed.

\section{Disclosure}

The authors report no conflicts of interest in this work.

\section{References}

1. Rohida NS, Bhad WA. Accidental ingestion of a fractured Twin-block appliance. Am J Orthod Dentofacial Orthop. 2011;139(1):123-125.

2. Sankar NS. Accidental ingestion of a dental instrument. $J R$ Soc Med. 1998;91(10):538-539.

3. Cooke LD, Baxter PW. Accidental impaction of partial dental prostheses in the upper gastrointestinal tract. Br Dent J. 1992;172(12):451-452.

4. Webb WA. Management of foreign bodies of the upper gastrointestinal tract: update. Gastrointest Endosc. 1995;41(1):39-51.

5. Nandi P, Ong GB. Foreign body in the esophagus: review of 2394 cases. Br J Surg. 1978;65(1):5-9.

6. Vizcarrondo FJ, Brady PG, Nord HJ. Foreign bodies of the upper gastrointestinal tract. Gastrointest Endosc. 1983;29(3):208-210.

7. Cheng W, Tam PK. Foreign-body ingestion in children: experience with 1265 cases. J Pediatr Surg. 1999;34(10):1472-1476.

8. Panieri E, Bass DH. The management of ingested foreign bodies in children - a review of 663 cases. Eur J Emerg Med. 1995;2(2):83-87.

9. Hachimi-Idrissi S, Corne L, Vandenplas Y. Management of ingested foreign bodies in childhood: our experience and review of the literature. Eur J Emerg Med. 1998;5(3):319-323.

10. Kay M, Wyllie R. Pediatric foreign bodies and their management. Curr Gastroenterol Rep. 2005;7(3):212-218.

11. Blaho KE, Merigian KS, Winbery SL, Park LJ, Cockrell M. Foreign body ingestions in the emergency department: case reports and review of treatment. J Emerg Med. 1998;16(1):21-26.

12. Tiwana KK, Morton T, Tiwana PS. Aspiration and ingestion in dental practice: A 10-year institutional review. J Am Dent Assoc. 2004;135(9): $1287-1291$. 
13. Abdullah BJ, Teong LK, Mahadevan J, Jalaludin A. Dental prosthesis ingested and impacted in the esophagus and orolaryngopharynx. J Otolaryngol. 1998;27(4):190-194.

14. Susini G, Pommel L, Camps J. Accidental ingestion and aspiration of root canal instruments and other dental foreign bodies in a French population. Int Endod J. 2007;40(8):585-589. Epub 2007 May 26.

15. Fields RT Jr, Schow SR. Aspiration and ingestion of foreign bodies in oral and maxillofacial surgery: a review of the literature and report of five cases. J Oral Maxillofac Surg. 1998;56(9):1091-1098.

16. Neves CZ, Maluf-Filho F. Clinical and endoscopic aspects of foreign body ingestion. Gastroenterol Hepatol. 2010;6(9):584-585.

17. Benjamin SB. Small bowel obstruction and the Garren-Edwards gastric bubble: an iatrogenic bezoar. Gastrointest Endosc. 1988; 34(6):463-467.

18. Chao HH, Chao TC. Perforation of the duodenum by an ingested toothbrush. World J Gastroenterol. 2008;14(27):4410-4412.

19. Meyns BP, Faveere BC, Van de Werf FJ, Dotremont G, Daenen WJ. Constrictive pericarditis due to ingestion of a toothpick. Ann Thorac Surg. 1994;57(2):489-490.
20. Shaffer RD. Subcutaneous emphysema of the leg secondary to toothpick ingestion. Arch Surg. 1969;99(4):542-545.

21. Bee DM, Citron M, Vannix RS, Gunnell JC, Bridi G, Juston G Jr, Kon DV. Delayed death from ingestion of a toothpick. $N$ Engl J Med. 1989;320(10):673.

22. Samarasam I, Chandran S, Shukla V, Mathew G. A missing denture's misadventure! Dis Esophagus. 2006;19(1):53-55.

23. European Radiology and Nuclear Medicine, UK Royal College of Radiologists, European Commission. Referral guidelines for imaging. European Communities- Luxembourg. Printed in Italy; 2001:94-115. Available at http://ec.europa.eu/energy/nuclear/radioprotection/ publication/doc/118_en.pdf.

24. Bisharat M, O'Donnell ME, Gibson N, et al. Foreign body ingestion in prisoners - the Belfast experience. Ulster Med J. 2008;77(2): $110-114$.
Therapeutics and Clinical Risk Management

\section{Publish your work in this journal}

Therapeutics and Clinical Risk Management is an international, peerreviewed journal of clinical therapeutics and risk management, focusing on concise rapid reporting of clinical studies in all therapeutic areas, outcomes, safety, and programs for the effective, safe, and sustained use of medicines. This journal is indexed on PubMed Central, CAS,

\section{Dovepress}

EMBase, Scopus and the Elsevier Bibliographic databases. The manuscript management system is completely online and includes a very quick and fair peer-review system, which is all easy to use. Visit http://www.dovepress.com/testimonials.php to read real quotes from published authors.

Submit your manuscript here: http://www.dovepress.com/therapeutics-and-clinical-risk-management-journal 